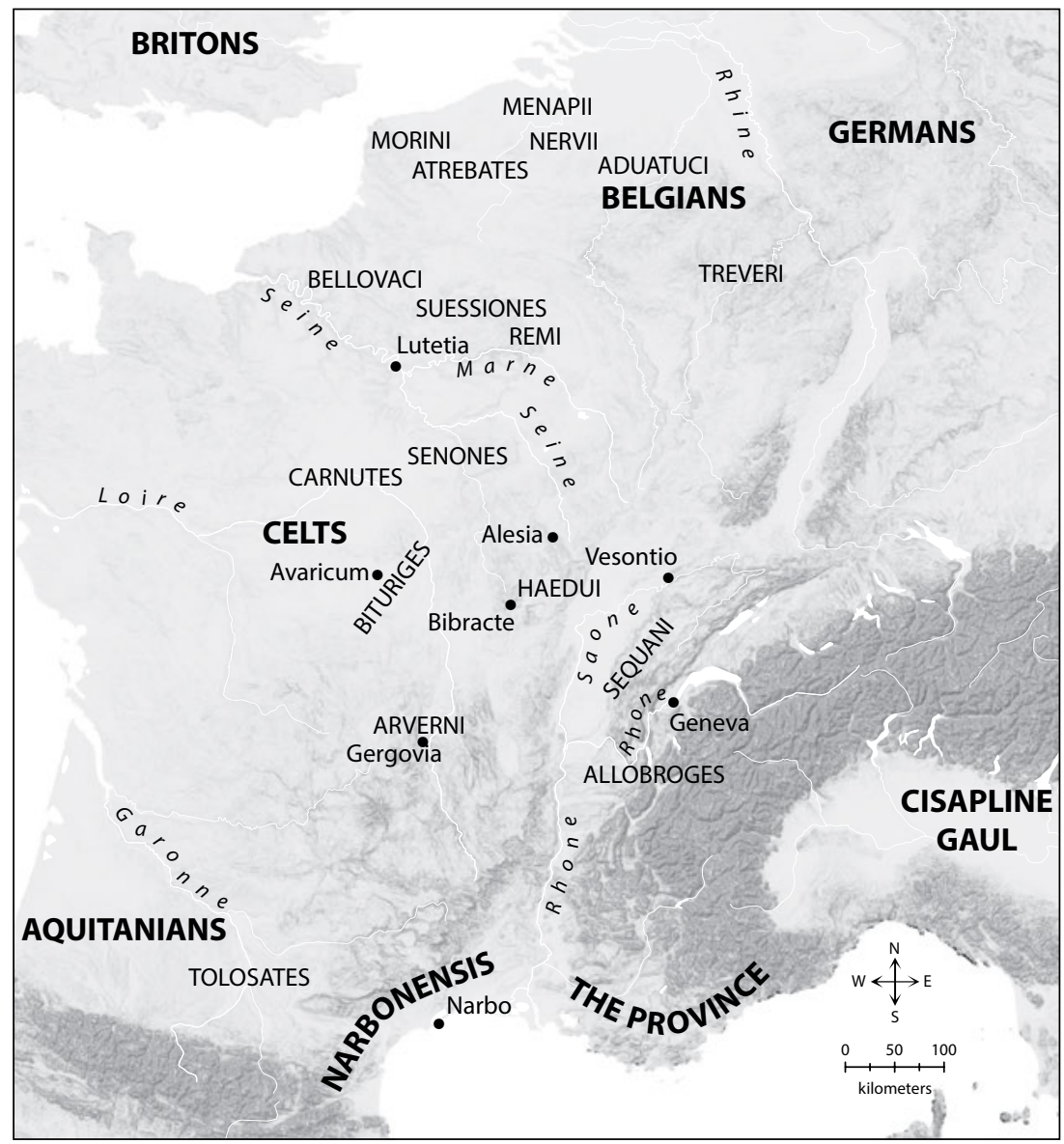

\title{
MAP OF GAUL
}

The wonderfully helpful modern maps that scholars have drawn over the last two centuries create a world nothing like the one Caesar and his contemporaries could have known. This map is intentionally drawn to approximate the knowledge that a Roman reader might have or have drawn from reading Caesar. It is still much too 
accurate for its purpose, showing the land masses, mountains, rivers, and seas as accurately as moderns know how to represent them. To make a mental adjustment for that, remember perhaps that the ancients believed that if you proceeded from Gaul to Britain to Ireland, the next land west to which you came was Spain. The best place to go further for a collection of online maps specific to Caesar is the splendid Dickinson College Commentaries site created by Professor Christopher Francese; the Caesar-in-Gaul maps page there is http://dcc.dickinson.edu/subjects/gallic-war-maps. The reader who wishes to explore the spaces and places of this book in more detail can also go to https://drive.google.com/open?id=1uSO QsaxXjm4BXxTUlzAJZv5JW4Fokug_\&usp=sharing or, more compendiously for the same thing, https://tinyurl.com/y8mgfp5g. On that map, I have marked with push pins every ancient place named in this volume with at least short explanatory notes. The map is searchable using either ancient or modern place names.

The best comprehensive atlas of the classical world is R. J. Talbert, ed., The Barrington Atlas of the Greek and Roman World (Princeton University Press, 2001). 

THE WAR FOR GAUL 
